\title{
The Overview of the Origin and Research of Rural Tourism Development
}

\author{
lu Tang ${ }^{1, a}$ \\ ${ }^{1}$ Shandong university, shandong, China, 264200 \\ a huanjingtl@vip.qq.com
}

\section{Keywords: Rural tourism; Overall review; Summary}

\begin{abstract}
TWith the accelerated process of urbanization in China and the continuous development of tourism, rural tourism is also flourishing across our country. After the 1950s, rural tourism has become a hot spot in foreign tourism research. In China, after 2000, rural tourism has also become the focus of scholars. At present, the study of rural tourism in our country is still at the initial stage, and there is still some controversy about the connotation of rural tourism. The author gives a new perspective and idea on the development and research of rural tourism according to the relevant literature at home and abroad to study the problems of rural tourism in practice.

In the development of tourism economy, a strong momentum, "going to the mountainous areas and the countryside" has become a new fashion for city people. The international tourist attraction has already changed from "4S"(Sun,Sea,Sand,Sex) to "4N" (Nature,Nostalgia, Nirvana, Native), which marks that people's interest in tourism has shifted from traditional sensual pleasure to spiritual enjoyment of green tourism. And the countryside gives tourists the latest experience with its beautiful scenery and rich cultural connotations. At the same time, the Three Rural Issues (the issue of agriculture, rural areas and farmers) is still an important issue in the development of China's national economy, and pro-poor tourism has been proved to be the most efficient and effective way. In order to make rural tourism develop in the direction we expect and get the maximization of utility, we must carefully study, think and plan the rural tourism, so as to find a scientific way to rural tourism development.
\end{abstract}

\section{The Origin of Rural Tourism at Home and Abroad}

The origin of rural tourism can be said an "old and young" form of tourism. It is old because rural tourism has existed since ancient times.It is young because the ancient rural tourism generally refers to visiting the relatives and friends in countryside and the picnic of scholars. It was a spontaneous and occasional travel behavior, which did not bring local economic benefits, increase employment opportunities, or form an industry. The rural tourism in its true sense is a new type of tourism activities appeared in the late 19th century, and vigorously developed after the "World War II".

There is a popular theory in present academic circle that rural tourism originated in France. Another argument is that rural tourism originated in the late 19th century in the United Kingdom because of the industrial revolution, which improved people's lives while giving them more rest time. The railway, which was constructed to accommodate the industrial development,

can send people safely and quickly outside their usual environment and provided disposable income, leisure time and appropriate media for rural tourism. In the early 1960s, Spain took the lead in transforming the barren aristocratic castles in the Catalan village into simple farmhouses and the large towns and farms were included in the scope of traveling and visiting, thus the popular modern rural tourism in its true sense developed. After 1970s, the rural tourism in the United States, Canada and other countries entered fast-growth stage. There is also a saying that rural tourism was born in Italy. In 1865, the establishment of the Italian "National Association of Agriculture and Tourism" marked the birth of rural tourism. Anyhow, people all agreed that the rural tourism originated in 19th century in Europe. In China, it's said that the rural tourism generated in 1950s in Shijiazhuang to meet foreign exchange affairs. But domestic scholar agree more that rural tourism originated in the 1980s in Shenzhen. In the late 1980s, Shenzhen opened the "litchi festival" in order to attract foreign investment,and then opened the picking garden, which achieved good results. So the 
sightseeing agriculture project was emulated by many cities. In 1998, the National Tourism Administration launched a theme of "China's urban and rural tourism", of which returning to nature's eco-tourism is an important content, after which the rural tourism developed rapidly, forming many distinctive rural tourist attractions. People can not only go sightseeing, but also work on holidays. There are also many agricultural festivals, such as "farmhouse" tourism project in Sichuan and village tourism in Guizhou. In addition, the flat peach picking garden in Pinggu District, Beijing City, watermelon picking garden in Daxing District, Beijing City, the flowers and trees park and tea picking and processing garden in Shimen Farm, Jinhua City, Zhejiang Province and litchi sightseeing and picking garden in Shenzhen City are China's famous rural tourism demonstration sites.

\section{The Research Status of Rural Tourism Research at Home and Abroad}

The Research Status of Rural Tourism Research Abroad. In 19th century, rural tourism has been favored by western urban residents for its leisure and peacefulness. The earliest studies of rural tourism should be traced back to the 1980s, when American scholar Hector Ceballos Lascurain created the word "ecotourism" in 1983, and then the number of related words reached 35, in which It contains "country tourism ". At present, the definitions of rural tourism in foreign academia mainly include the following views. Spanish scholar Gilbert and Tung argue that rural tourism is a form of tourism in which farmers provide accommodation and other conditions for tourists to engage in various recreational activities in typical rural environments such as farms and pastures. Arie Reichel and Oded Lowengart from Israel and Ady Milman from the United States concisely said: "Rural tourism is tourism located in rural areas."These two kinds of argument represent the narrow and broad sense of rural tourism connotation.

In the key to the development of rural tourism business and its sense, the World Economic Cooperation Organization stressed that rurality is the center and unique "selling point" of rural tourism. The key to maintaining rurality are small-scale operations, local ownership, community participation and culture and environmental sustainability. Dernoi pointed out that rural tourism is a tourism activity that occurs in non-urban areas where there are permanent residents and is an economic activity, basically agricultural activity, which occured closely related to land. He also clearly pointed out that the existence of permanent residents is a requirement for rural tourism and that rural tourism is the follow-up or alternative industry to traditional agriculture. Rural tourism provides farmers with a second source of income, increases employment opportunities, reduces population losses, and brings new ideas to the city. It gives urban people the opportunity to experience rural life and raises their awareness of rural issues. It has contributed to the diversification of the rural economy, which is conducive to the transformation of infrastructure. Especially, it is the decline of the rural areas in Europe for centuries and in the US for about 80 years that makes the role of rural tourism increasingly important. A large number of foreign research literature shows that although the development of rural tourism in the world is not as good as other tourism development models, people have already reached a consensus on its functions in developing the rural economy, solving the employment of farmers, relaxing the city people and other issues.

\section{The Research Status of Rural Tourism}

Research at Home.Although China's rural tourism research started late, it received sufficient attention. There are many relevant definitions at home.(Table 1) 
Table 1 The Definitions of Rural Tourism

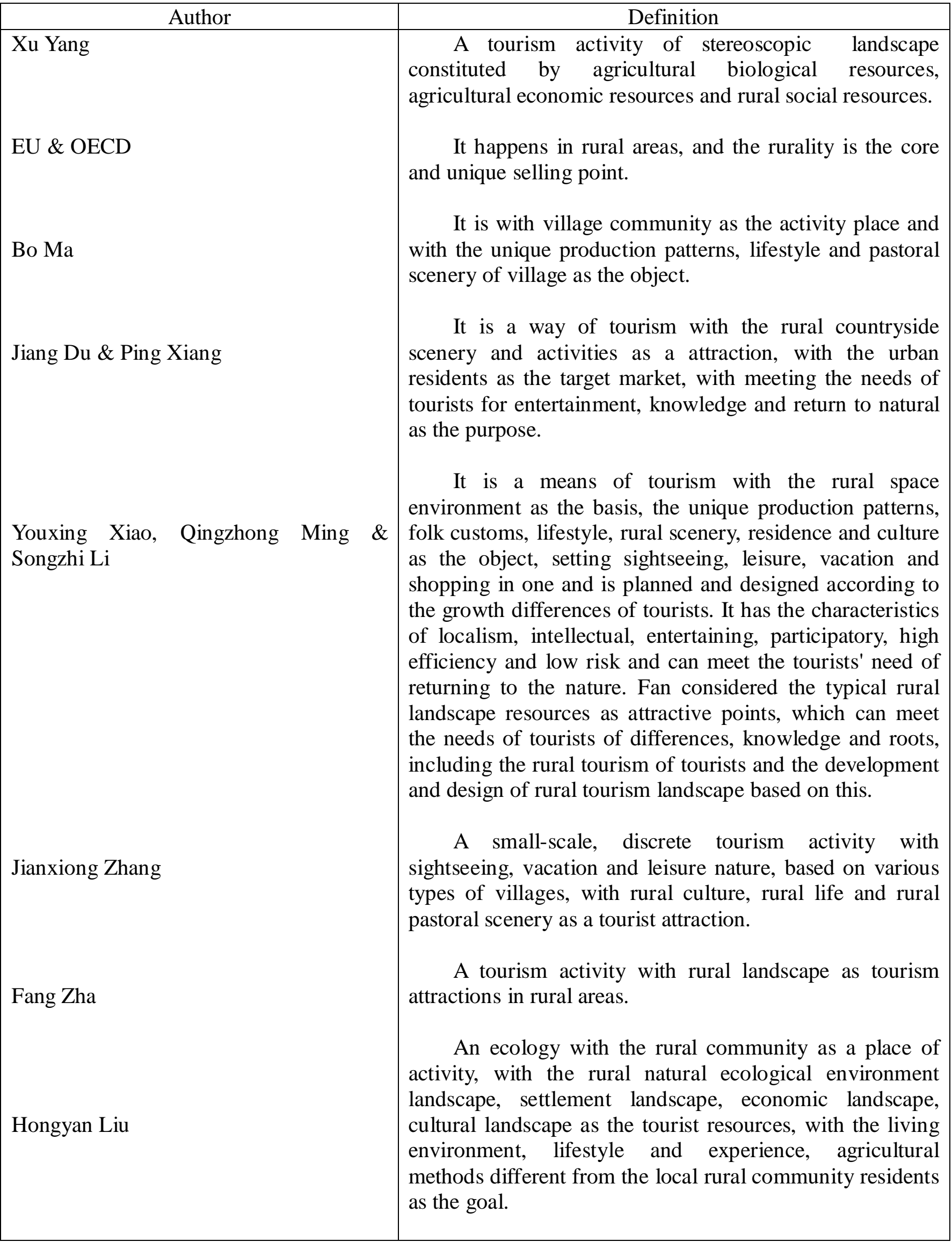




\section{Definition of Rural Tourism.}

\section{The definition of concept relates to the construction of theory. The incomplete and inaccurate understanding of the concept of rural tourism}

In China may lead to the deviation of the theoretical research system of rural tourism, thus leading to the simplification of development mode and operation model of rural tourism. At present, the formulations of ecological agriculture tourism, sightseeing agriculture, and green tourism interfere with the thoughts of researchers and rural tourism operators to some extent. Therefore, in order to better study the rural tourism, it is significant to define its concept and clarify the connotation and extension. On the basis of the existing viewpoints, this paper expounds how to define the rural tourism from the perspective of the three elements of tourism activities.

The Subject of Tourism. In the existing definition, Du Jiang, Xiang Ping mentioned "target market" for the first time in 1999 to define the rural tourism. Liu Hongyan further defined the "target market" as the residents whose living area, lifestyle, experience, and the way of farming were different from the local rural community residents. According to the three elements of tourism activities, "target market" belongs to the subject of tourism, which includes tourism development, operators and tourists in the full sense. It is noteworthy that the existing definition has no discussion about development and management, another subject of rural tourism. And the excessive and overspeed development of some areas are fundamentally contrary to the original intention that the rural tourism is strongly supported by the whole country, violating the "income subject" status of farmers. Therefore, the author believes that the extensive financing is the prerequisite for the development of rural tourism. It is decided by the special status of rural tourism in China's rural economic development that the subject of development and management of rural tourism should only be local residents and the development of rural tourism must address the promotion of rural economic development and benefit the farmers.

The Object of Tourism. Through Table 1 we can easily find that the definition of rural tourism always involves in the object of rural tourism from either way.Gilbert and Tung confined the object of rural tourism to farms and pastures. Wu Bihu defined the rural tourism as the sum of tourism activities in rural and natural environment. As a result, "country and rural tourism resources" has become the problem to be solved before defining the rural tourism. The modern geography dictionary defines the country as relatively independent regional association administered by specific economy, society and nature occurring when the social productivity developed to a certain stage. In fact, the village is a concept relative to the town. The rural areas in China mainly refer to the areas outside the cities of national administrative system. The village in its narrow sense, which we usually talk about,mainly refers to the areas with agriculture being their main source of income, but the generalized villages also include non-urban areas like suburban areas and towns. Therefore, the rural tourism resources are tangible and intangible, natural and humanistic things related to rural life and naturally exist in rural areas, which can be used by tourism and can attract tourists, resulting in economic, social and ecological effects. With its unique cultural connotation and simple local flavor, rural tourism resources deeply attracted a new generation of tourists. The author believes that to some extent, the connotation and extension of villages and rural tourism resources are exaggerated or narrowed at present academia, but what we are sure is that although not all the tourism happened in villages belongs to rural tourism, rural tourism resources which is the object of rural tourism must exist in rural areas and its destination can only be rural community different from cities.

The Media of Tourism. Travel agency, as one of the tourism media, plays an important role in the traditional tourism and links the destination and source market, but was weakened with the rise of new means of traveling. From this point, to meet people's spiritual pursuit of returning to their original nature,the main forms of rural tourism are the experience and enjoyment of rural life, folk customs and natural scenery, which varies the collocation of time and distance. Farmhouse tourism represented by Sichuan is mainly within a short time and distance, tourists will choose the surrounding distance closer to the destination, in which the travel agency can be ignored.The special 
form of activities of rural tourism decreased the profit of travel agencies, and we must pay special attention to the survival and development of travel agencies and other media that exist in similar situations. Based on the definitions of rural tourism in academia, the author thinks that rural tourism, which weakens the roles of medium like travel agency compared with the traditional travel, is with the the farmers as the main body of development and interests, with the urban residents whose living environment is different from the rural community as the target market, with the rural tourism resources as the main attraction and with returning to nature as the main purpose. Among them, rural tourism resources are tangible and intangible, natural and humanistic things related to rural life and naturally exist in rural areas, which can be used by tourism and can attract tourists, resulting in economic, social and ecological effects.

\section{Conclusion}

China is an ancient agricultural country, so far the rural area still accounts for $90 \%$ of the land area and the rural population accounts for more than $70 \%$ of the total population. The social and economic conditions of rural areas have seriously hindered the development of our country. Rural tourism is known as the quickest and most effective way to solve the problem of agriculture, rural areas and farmers. The special status and role of rural tourism determines that it deserves our long-term concern. In the future research, the author believes that the whole and local case studies should be carried out on the basis of scientific definition, from surface to point and then from point to surface, puting forward the development way of rural tourism with universal guiding significance, combined with the local characteristics.

\section{Reference:}

[1] B. H. Wu. The Principle of Regional Tourism Planning[M]. Beijing: China Travel \& Tourism Press, 2001:270-271.(In Chinese)

[2] X. Yang. It is Imperative to Develop Rural Tourism[J]. Tourism Tribune, 1992, 7(2):38-41.(In Chinese)

[3] A. Reichel, O. Lowengart \& A. Milman. Rural Tourism in Israel: Service Quality and Orientation[J]. Tourism Management, 2000, (21):451-459.(In Chinese)

[4] B. Ma. On the Development of Rural Tourism in Guanzhong Region[A]. Chinese Tourism geographical committee of the Geographical Society. Theory and Practice of Regional Tourism Development[C]. Nanjing: Jiangshu People's Press, 1996.(In Chinese)

[5] J. Du. \& P.Xiang. Thoughts on Sustainable Development of Rural Tourism[J]. Tourism Tribune, 1999,(1):15-18.(In Chinese)

[6] Y. X. Xiao, Q. Z. Ming \& S. Z. Li. On the Concept and Types of Rural Tourism[J]. Tourism Science, 2001,(3):8-10.(In Chinese)

[7] C. Fan. On the Development of Rural Tourism[J]. Journal of Yuzhou University (JCR-SSCI), 2002,19(5):20-23.(In Chinese)

[8] J. X. Zhang. Reflections on Some Problems of Rural Tourism[A]. Journal of Dali University, 2003,(4):11-16. (In Chinese)

[9] F. Zha. Studying on the Origin and Definition of Rural Tourism[A]. Journal of Ankang Normal University, 2004,(16):29-32. (In Chinese)

[10][H. Y. Liu. Thinking about the Connotation of Rural Tourism[A]. Journal of China West Normal University (Philosophy and Social Science Edition), 2005,(2):15-18. (In Chinese) 